\title{
Effect of Adiposity on Plasma Visfatin and Retinol Binding Protein-4 with and without Type 2 Diabetes Mellitus
}

\author{
Amal El-Shehaby, Abir Zakaria*, Naglaa Mostafa** and \\ Soha Talaat** \\ The Departments of Medical Biochemistry, Internal Medicine* and \\ Radiology** Faculty of Medicine- Cairo University
}

\begin{abstract}
Visceral and subcutaneous adipose tissue display important metabolic differences that underline the association of visceral obesity with obesity-related cardiovascular and metabolic alterations. Recently, the potential role of adipokines (visfatin and retinol binding protein-4) in the development of obesity-related insulin resistance are increasingly understood. The aim of the present study was to investigate whether plasma visfatin and retinol binding protein-4 (RBP-4) levels are correlated with obesity and type 2 diabetes mellitus and to examine their association with visceral, subcutaneous as well as fat deposition in the liver. The study was conducted on forty patients with type 2 diabetes mellitus and twenty age and sex matched healthy subjects as controls. Both diabetic and control subjects were divided into two equal groups according to the body mass index (BMI), the first was non-obese subjects with $B M I<25 \mathrm{Kg} / \mathrm{m}^{2}$ and the other was obese subjects with $\mathrm{BMI} \geq 30 \mathrm{Kg} / \mathrm{m}^{2}$ (20 cases each). After full clinical evaluation, fasting plasma glucose, glycosylated hemoglobin, and lipid profile levels were estimated in all groups. Plasma visfatin, retinol binding protein-4 and serum insulin levels were measured by enzyme-linked immunosorbent assay. Insulin resistance index was calculated by the homeostasis model assessment $\left(H O M A_{I R}\right)$. Visceral fat, subcutaneous fat and fat deposition in the liver were measured by ultrasonography. The results of the study showed that the levels of plasma visfatin and RBP-4 were increased significantly in diabetics compared to control group; moreover, both of them were significantly higher in diabetics compared to control subjects with similar BMI values. However, Plasma visfatin concentration was positively correlated with RBP-4, BMI, waist / hip ratio (WHR), insulin, insulin resistance index and visceral fat area, while it was negatively correlated with systolic blood pressure in all diabetic patients (both obese and nonobese). On the other hand, plasma RBP-4 concentration was correlated positively with visfatin, BMI, WHR, blood glucose, insulin and insulin resistance index, and ectopic fat deposition in the liver in diabetic patients. Stepwise multiple regression analysis revealed that plasma visfatin levels remained positively correlated with visceral fat area and WHR; while plasma RBP-4 levels remained positively correlated with BMI, ectopic fat deposition in the liver and HOMA IR in all diabetic patients. Plasma visfatin levels were significantly higher in diabetics than control subjects and positively correlated with visceral fat area but not with subcutaneous fat.
\end{abstract}


Although visfatin levels were increased in type 2 diabetes mellitus, the correlation seems to be primarily through obesity. Moreover, plasma RBP-4 levels were increased significantly in diabetics compared to control subjects. However, circulating RBP-4 is not correlated with the amount of visceral or subcutaneous fat, but, it was correlated positively with ectopic fat deposition in the liver and insulin resistance. Thus, the close relationship between circulating RBP-4 with ectopic fat deposition in the liver and insulin resistance may reflect stronger effects of RBP-4 on hepatic insulin sensitivity.

\section{INTRODUCTION}

An increased adipose tissue mass is strongly associated with the pathogenesis of insulin resistance and type 2 diabetes ${ }^{(\mathbf{1})}$.Besides its role in energy storage, adipose tissue, an endocrine organ, produces several hormones and cytokines (such as leptin, tumor necrosis factor- $\alpha$, interleukin-6, and adiponectin) that have wide-ranging effects on carbohydrates and lipid metabolism, and therefore appear to play an important role in the pathogenesis of diabetes, insulin resistance and atherosclerosis ${ }^{(2)}$. However, it is apparent that accumulation of visceral adipose tissue has a greater cardiometabolic risk than subcutaneous adipose tissue, even though subcutaneous adipose tissue depot was the largest of the two ${ }^{(3)}$; removal of visceral than subcutaneous tissue improves insulin sensitivity ${ }^{(4)}$. Additionally, differences in gene expression between adipocytes of visceral or subcutaneous origin do exist. The potential role of recently discovered adipokines (visfatin and retinol binding protein-4) in the development of obesity- related insulin resistance are increasingly understood.

Visfatin was recently identified as a protein highly expressed in visceral adipose tissue compared to subcutaneous adipose tissue ${ }^{(5)}$, previously known as a pre-B-cell colony-enhancing factor (PBEF), has a function also in the immune system, where it was described as a growth factor for early B-cells ${ }^{(6)}$. Visfatin (PBEF) binds and activates the insulin receptor in different insulin-sensitive cells in vitro and treating mice with recombinant visfatin elicited insulinlike effects, also in vivo. Plasma glucose is lowered by treatment with visfatin, while heterozygous mice knockout for the visfatin gene have plasma glucose levels higher than wild-type littermates ${ }^{(5)}$. Visfatin expression in adipocytes is upregulated by dexamethazone and is downregulated by growth hormone, isoproterenol, and cholera toxin. Insulin has no effect on visfatin mRNA (7). Moreover, visfatin is upregulated by peroxisome proliferators-activated receptor (PPAR $\alpha$ and PPAR $\gamma$ ) agonists in obese rats in association with improved glycaemic control and lipid profile, thus suggesting that PPAR $\alpha$ and $\operatorname{PPAR} \gamma$ agonists may act, at least in part, through the upregulation of visfatin expression ${ }^{(8)}$. A recent study in humans reported plasma visfatin to be directly correlated with body mass index and body fat content in males only and failed to find a different 
expression of visfatin mRNA between visceral and subcutaneous fat depots ${ }^{\text {(9) }}$.Although, plasma levels of visfatin increased with obesity and correlated positively with visceral adiposity ${ }^{(\mathbf{1 0})}$, others did not notice that association $^{(\mathbf{9})}$.

Retinol-binding protein (RBP)-4, secreted by liver and adipocytes, has important effects on systemic insulin sensitivity and glucose homeostasis $^{(11)}$. Serum RBP-4 levels are elevated in insulin resistant states both in mice and humans. In mice, intraperitoneal injection of recombinant human RBP-4 induces systemic insulin resistance. Treatment of insulin-resistant mice with rosiglitazone, peroxisome proliferators activated receptor PPAR $\gamma$ agonist that improves insulin sensitivity, completely normalizes elevated RBP-4 levels and reverses insulin resistance ${ }^{(\mathbf{1 2})}$. Elevation of RBP-4 might therefore play a causative role in insulin resistance and type 2 diabetes mellitus. In humans, serum RBP-4 levels correlate with the magnitude of insulin resistance and components of the metabolic syndrome. Improvement of insulin sensitivity by exercise training is associated with a reduction in serum RBP-4 levels ${ }^{(11)}$. Recently, serum RBP-4 levels were shown to be strongly correlated with the trunkal obesity and not with peripheral obesity $^{(13)}$. However, Stefan et al. ${ }^{(14)}$ did not show any correlation between RBP-4 and either visceral or subcutaneous fat.

Effective methods for assessing visceral fat are important to investigate its role in the increased health risks in obesity. Simple anthropometric methods, such as waist-to-hip circumference ratio, waist circumference or sagittal diameter are widely used. However, these methods cannot differentiate between visceral and subcutaneous fat and are less accurate ${ }^{(\mathbf{1 5})}$. Dual energy x-ray absorptiometry (DEXA) measures body mass index, percentage of fat and total body fat mass ${ }^{(\mathbf{1 6})}$.There have been a considerable number of researches involved in determining each component of body fat mass and body fat distribution. These methods are computerized tomography $(\mathrm{CT})^{(\mathbf{1 7})}$ and magnetic resonance imaging $(\mathrm{MRI})^{\mathbf{( 1 8 )}}$ the latter made it possible to assess subcutaneous fat (SF), and visceral fat (VF) area. However, they are expensive, time consuming and require a relatively high radiation $\operatorname{dose}^{(\mathbf{1 6 )}}$. Moreover, in 1992, the method using abdominal ultrasonography (US) for assessment of subcutaneous fat thickness was reported, which made it possible to assess abdominal fat distribution in each individual frequently and repeatedly ${ }^{(\mathbf{1 9 )}}$.Ultrasonography is a new, simple and accurate method of measuring visceral fat area. Moreover, it can differentiate subcutaneous from visceral fat area ${ }^{(20)}$.

The main objectives of the current study were to investigate the role of visfatin and retinol binding protein 4 in type 2 diabetes mellitus and obesity and to measure the visceral and subcutaneous abdominal fat as well as ectopic fat deposition in the liver using ultrasound, and whether these measures would be correlated with plasma visfatin and RBP-4. 


\section{MATERIAL \& METHODS}

A total of forty patients with type 2 diabetes mellitus (19 males and 21 females, with a mean age of $50.3 \pm$ 3.8 years and a duration of diabetes of $6.0 \pm 3.2$ years) were recruited from Internal Medicine Outpatient Clinics at Kasr El-Aini Hospital, as well as forty normal healthy adults (20 males and 20 females, with a mean age of $50.2 \pm 3.6$ years) from medical and paramedical staff personals participated as control group. An informed consent was taken from all participants. The subjects chosen for the study were categorized based on their body mass index (BMI) as nonobese (BMI $<25 \mathrm{~kg} / \mathrm{m} 2)$ and obese (BMI $\geq 30 \mathrm{~kg} / \mathrm{m}^{2}$ ). Obesity was defined according to the World Health Organization criteria on the basis of the body-mass index (BMI) (the weight in kilograms divided by the square of the height in meters) ${ }^{(21)}$. Diagnosis of type 2 diabetes mellitus was made according to the American Diabetes Association. They considered an individual to be diabetic if fasting plasma glucose (FPG) was $\geq$ $126 \mathrm{mg} / \mathrm{dl}$ and/or taking treatment for diabetes $^{(22)}$. Additionally, in the current study first and second degree relatives of type 2 diabetic patients were excluded from the control group. The diabetic patients were treated with diet and the oral hypoglycaemic drug metformin or sulfonylurea. No patients were receiving thiazolidinediones or insulin. Patients who had a diagnosis of urinary tract infection, urolithiasis, liver cirrhosis, hypertension, ischemic heart disease, macrovascular disease, overt proteinuria, or other known major diseases were excluded from the study.

The following investigations were performed for all subjects:

Detailed history taking and physical examination to exclude the presence of cardiac, hepatic, renal, gastrointestinal or malignant disease which might affect the parameters to be investigated. Blood pressure was measured to exclude the presence of hypertension. Anthropometric measurements including: Body mass index (BMI) and Waist to hip ratio (WHR) were calculated for each participant. Waist and hip circumferences were measured. The waist circumferences were measured to the nearest $0.1 \mathrm{~cm}$ at the narrowest point between the lowest rib and the uppermost lateral border of the right iliac crest. The hips were measured at their widest point.

\section{Biochemical analysis}

Venous blood samples were collected after 12 hour overnight fast from all subjects and divided into parts. Part of blood sample was withdrawn on $\mathrm{K}_{2}$ EDTA for plasma separation and the separated plasma was kept frozen at $-80^{\circ} \mathrm{C}$ for further determination of Visfatin, Retinolbinding protein- 4 , and insulin. The other part was taken as whole blood on $\mathrm{K}_{2}$ EDTA for determination of glycosylated hemoglobin $\left(\mathrm{HbA}_{\mathrm{cc}}\right)$ by spectrophotometic method using kit provided by Stanbio, Texas, USA ${ }^{(\mathbf{2 3})}$. The third part was allowed to clot. The separated serum was used for determination of triacylglycerol ${ }^{(24)}$; total cholesterol ${ }^{(25)}$, high density lipoprotein cholesterol (HDL-c) and low density lipoprotein cholesterol $(\mathrm{LDL}-\mathrm{c})^{\mathbf{( 2 6 )}}$ using commercially 
available kits. The last part was collected on fluoride for estimation of fasting plasma glucose by glucose oxidase-peroxidase method ${ }^{(27)}$. Fasting plasma insulin was assessed by the ELISA kit provided by BioSource, Nivelles, Belgium. Plasma visfatin levels were estimated by the ELISA kit provided by Phoenix Pharmaceuticals, Belmont, CA, USA. Assay sensitivity was $2 \mathrm{ng} / \mathrm{ml}$ and inter-assay and intra-assay Coefficient Variation $(\mathrm{CV})$ were $<10 \%$ and $<5 \%$ respectively. Plasma Retinol-binding protein 4 levels (RBP-4) were measured by the ELISA kit provided by BioSource, Nivelles, Belgium. Assay sensitivity was between 0.001 and $5 \mu \mathrm{g} / \mathrm{ml}$ with inter-assay and intra-assay $\mathrm{CV} \quad 5 \quad \% \quad-4.6 \%$ respectively. Insulin sensitivity was calculated using the homeostatic model assessment ( $\left.\mathrm{HOMA}_{\mathrm{IR}}\right)$ index with the formula: fasting plasma glucose $(\mathrm{mmol} / \mathrm{l}) \times$ fasting plasma insulin $(\mu \mathrm{IU} / \mathrm{ml}) / 22.5^{(\mathbf{2 8})}$.

\section{Body fat distribution}

Thirty seven subjects were examined by US machine (Siemens, Elegra) and forty three subjects were examined using (General Electric, voluson pro) US machine. Screening of the abdomen was done for assessment of the liver for presence of fatty changes, and then visceral fat thickness in different sites and subcutaneous fat were measured by two experienced sonographers while the patient was in the supine position during normal quite respiration.

A $3.5-5 \mathrm{MHz}$ convex-array probe was used to measure the first three parameters. The distance between the abdominal muscles and the splenic vein was scanned transversely in the mid line. In some cases of obese participants, the splenic vein was unclear in the mid line due to increased visceral fat in the mid line, so we tried to take that measurement in the anterior axillary line searching for the splenic vein at the splenic hilum. When the splenic vein could not be visualized clearly, that vein was detected by using color Doppler flow (Figure 1). The distance between the abdominal muscles and posterior wall of the aorta was measured; also, transversely in the mid line on the umbilicus (Figure 2). The thickness of the fat layer of the posterior right renal wall was scanned longitudinally in the right anterior axillary line (Figure 3). For the fourth measurement (the thickness of the subcutaneous fat), it was measured using $7.5 \mathrm{MHz}$ linear-array probe. The volume of visceral fat was measured according to the following equation quoted from Hikoora et al: Visceral fat area $($ VFA $)=-9.008+1.191 \times($ The distance between the internal surface of the abdominal muscle and the splenic vein) $+0.987 \times$ (The distance between the internal surface of the abdominal muscle and the posterior wall of the aorta on the umbilicus in $\mathrm{mm}$ ) $+3.644 \mathrm{x}$ (thickness of the fat layer of the posterior right renal wall in $\mathrm{mm})^{(\mathbf{2 0})}$.The visceral fat area of over $100 \mathrm{~cm}^{2}$ is widely accepted in diagnosing visceral fat obesity ${ }^{(15)}$. 


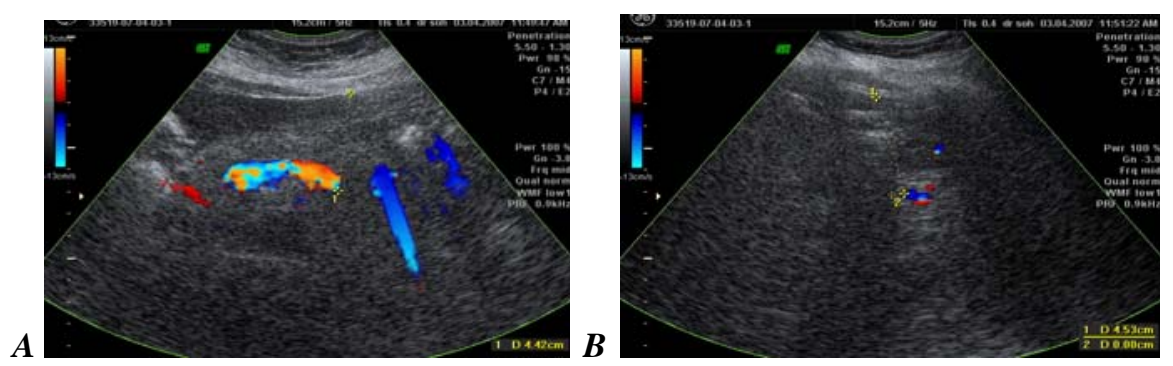

Figure 1: A- shows measuring the distance between splenic vein and abdominal wall muscles in mid line. B- Measurement in anterior axillary line, both are comparable.
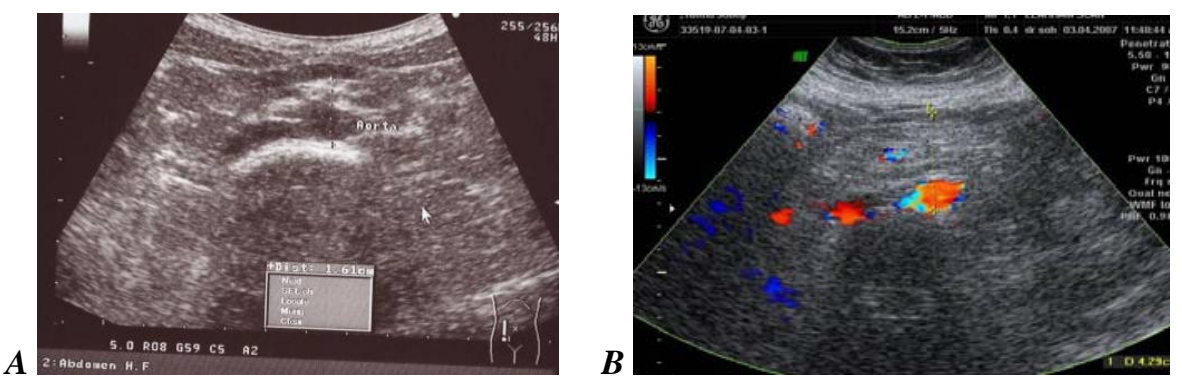

Figure 2: Measurement of visceral fat from abdominal muscles to posterior aortic wall. A. In non obese control. B. Complementary color Doppler is used in that case (obese control) for better visualization of the aorta.

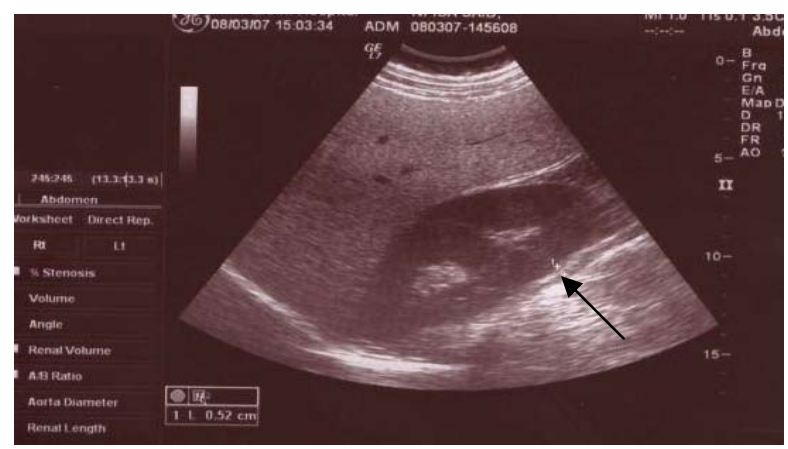

Figure 3: Showing measurement of posterior renal fat (arrow) in obese female diabetic patient. Note also the presence of enlarged liver with bright echopattern (fatty liver). 


\section{Statistical analysis}

Statistical Package for social science (SPSS) program version 9.0 was used for analysis of data. Data was summarized as mean \pm SD. t - test was used for analysis of 2 quantitative data. One way ANOVA was done for analysis of more than two variables followed by post HOC test for detection of significance. Simple linear correlation (Pearson's correlation) was used for quantitative data. It was done to detect the relation between the Visfatin and RBP-4 with all other demographic and laboratory data. " $r$ " value was considered weak if $<0.25$, mild if $\geq 0.25-<0.5$, moderate if $\geq 0.5-<0.75$ and strong if $\geq 0.75^{(29)}$. Stepwise multiple regression analysis was done for detection of independent determining factors for visfatin and RBP-4 levels. P-value is considered significant if $\leq 0.05^{*}$.

\section{RESULTS}

The clinical characteristics of the study groups (mean $\pm \mathrm{SD}$ ) are shown in table 1 . A total of 40 patients with type 2 diabetes mellitus and 40 sex and age matched nondiabetic subjects were studied. Diabetic patients had significantly higher mean values of fasting plasma glucose (FPG), insulin, $\mathrm{HOMA}_{\mathrm{IR}}$, total cholesterol, triacylglycerol, LDL-c, uric acid,
$\mathrm{HbA}_{1 \mathrm{c}}$ and systolic blood pressure (SBP) than those of control subjects. While, mean values of HDL-c were significantly lower in diabetics than control subjects. The mean value of plasma visfatin levels was found to be significantly higher in diabetic patients compared to control subjects $(44.1 \pm 13.4$ vs. $32.8 \pm 14.7 \mathrm{ng} / \mathrm{ml}$, $\mathrm{p}<0.001$ respectively) as well as plasma RBP-4 (46.3 \pm 10.3 vs. $26.8 \pm$ $7.5 \mu \mathrm{g} / \mathrm{ml}, \mathrm{p}<0.001$ respectively). As regards visceral fat area (VFA), the mean value was significantly higher in diabetic patients than in control subjects $(95.2 \pm 15.6$ vs. $83.3 \pm 21.4$ $\left.\mathrm{cm}^{2}, \quad \mathrm{p}<0.006\right)$. However, no significant difference was found between diabetic and control subjects in age, BMI, WHR, diastolic blood pressure (DBP), and subcutaneous fat (SF) thickness $(13.7 \pm 6.1$ vs. $11.8 \pm$ $4.5 \mathrm{~mm}, \quad \mathrm{p}>0.1)$. No gender differences were observed in any of the studied parameters with mean plasma visfatin levels in diabetics were $44.7 \pm 12$ in males vs. $43.6 \pm$ $14.9 \mathrm{ng} / \mathrm{ml}$ in females, $\mathrm{p}>0.8$ ) and in control subjects were $30 \pm 11.1$ in males vs. $35.2 \pm 17.2 \mathrm{ng} / \mathrm{ml}$ in females, $p>0.3$ ). Mean plasma RBP4 levels in diabetics were $46.4 \pm 10$ in males vs. $46.1 \pm 10.7 \mu \mathrm{g} / \mathrm{ml}$ in females, $\mathrm{p}>0.9$ ) and controls were $26.7 \pm 6.4$ in males vs. $26.9 \pm 8.5$ $\mu \mathrm{g} / \mathrm{ml}$ in females, $\mathrm{p}>0.9$ ). 
Table 1: Clinical characteristics of the studied subjects

\begin{tabular}{|c|c|c|c|}
\hline Variables & $\begin{array}{l}\text { Diabetics } \\
\text { Mean } \pm S D \\
N=40\end{array}$ & $\begin{array}{l}\text { Controls } \\
\text { Mean } \pm S D \\
N=40\end{array}$ & p-value \\
\hline Age (yrs) & $50.3 \pm 3.8$ & $50.2 \pm 3.6$ & $>0.9$ \\
\hline$B M I\left(\mathrm{~kg} / \mathrm{m}^{2}\right)$ & $28.1 \pm 6.2$ & $27.8 \pm 5.9$ & $>0.8$ \\
\hline WHR & $0.9 \pm 0.2$ & $0.9 \pm 0.2$ & $>0.9$ \\
\hline$S B P(m m H g)$ & $130.4 \pm 8.1$ & $121.4 \pm 7.4$ & $<0.001^{*}$ \\
\hline $\mathrm{DBP}(\mathrm{mmHg})$ & $79.5 \pm 8.2$ & $76.8 \pm 5.7$ & $>0.09$ \\
\hline FPG (mg/dl) & $193.1 \pm 39.1$ & $93.5 \pm 6.7$ & $<0.001 *$ \\
\hline Insulin $(\mu I U / m I)$ & $24.7 \pm 4.5$ & $10.1 \pm 3.4$ & $<0.001^{*}$ \\
\hline$H O M A_{I R}$ & $11.6 \pm 3.1$ & $2.3 \pm 0.9$ & $<0.001^{*}$ \\
\hline Total Cholesterol (mg/dl) & $211.9 \pm 24.2$ & $193.9 \pm 16.4$ & $<0.001 *$ \\
\hline Triacylglycerol (mg/dl) & $127.9 \pm 32.3$ & $114.0 \pm 22.8$ & $<0.03 *$ \\
\hline$H D L-c(m g / d l)$ & $41.0 \pm 7.9$ & $50.0 \pm 5.1$ & $<0.001 *$ \\
\hline$L D L-c(m g / d l)$ & $144.1 \pm 24.5$ & $119.7 \pm 15.8$ & $<0.001 *$ \\
\hline$H b A_{1 c}(\%)$ & $7.9 \pm 1.4$ & $5.7 \pm 0.3$ & $<0.001 *$ \\
\hline Visfatin ( $\mathrm{n} / \mathrm{ml})$ & $44.1 \pm 13.4$ & $32.8 \pm 14.7$ & $<0.001^{*}$ \\
\hline$R B P-4(\mu g / m l)$ & $46.3 \pm 10.3$ & $26.8 \pm 7.5$ & $<0.001 *$ \\
\hline Visceral fat area $\left(\mathrm{cm}^{2}\right)$ & $95.2 \pm 15.6$ & $83.3 \pm 21.4$ & $<0.006^{*}$ \\
\hline SF thickness (mm) & $13.7 \pm 6.1$ & $11.8 \pm 4.5$ & $>0.1$ \\
\hline \multicolumn{4}{|c|}{ p-value is significant if $\leq 0.05 * \quad *$ Different symbols indicate significance } \\
\hline \multirow{5}{*}{\multicolumn{4}{|c|}{$\begin{array}{l}\text { BMI: Body mass index WHR: Waist hip ratio SBP: Systolic blood pressure } \\
\text { DBP: Diastolic blood pressure FPG: Fasting plasma glucose } \\
\text { SF: Subcutaneous fat HOMA } A_{I R}: \text { Homeostatic model assessment of insulin resistance } \\
\text { HDL-c: High density lipoprotein cholesterol } \\
\text { LDL-c: Low density lipoprotein cholesterol }\end{array}$}} \\
\hline & & & \\
\hline & & & \\
\hline & & & \\
\hline & & & \\
\hline \multicolumn{4}{|c|}{$H b A_{I C}:$ Glycosylated hemoglobin $\quad R B P-4:$ Retin } \\
\hline
\end{tabular}

Table 2 shows that there was a significantly higher mean value of visfatin levels in diabetic groups as compared to that in control groups $(\mathrm{p}<$ 0.001). Furthermore, mean visfatin levels were significantly higher in diabetic patients compared with controls with similar BMI values $(\mathrm{p}<$ 0.001 ), while mean values of plasma RBP-4 level of non-obese and obese diabetics were significantly higher in comparison to non-obese and obese control group respectively $(\mathrm{p}<0.001)$. Moreover, mean RBP-4 level of obese diabetic participants was, also, significantly higher than that of nonobese diabetic group $(p<0.001)$. There were significant differences in the mean values of blood lipid profile, systolic blood pressure, and $\mathrm{HbA}_{\mathrm{lc}}$, levels between diabetics and controls. Mean value of cholesterol levels in non-obese and obese diabetic patients was significantly higher than that in control group with similar BMI respectively $(\mathrm{p}<0.001)$, but there was no significant difference between nonobese and obese diabetics. Mean values of triglyceride levels was significantly higher in both obese and 
non-obese diabetics when compared to non-obese controls, while; no significant difference was observed between obese control and both diabetics (obese and non-obese) and non-obese controls. The mean values of fasting insulin levels as well as $\mathrm{HOMA}_{\mathrm{IR}}$ were significantly different among the four studied groups $(\mathrm{p}<$ $0.001)$. The mean value of fasting plasma glucose levels in diabetics was significantly higher than that in control groups with similar BMI, and there was a significant difference between non-obese and obese diabetic $(\mathrm{p}<0.001)$. As regards BMI, WHR, visceral fat area and subcutaneous fat thickness, there were significant differences between obese and nonobese groups in both diabetics and control subjects. But there were no significant differences neither between obese diabetics and obese control nor non-obese diabetics and non-obese control; except for there was a significantly higher visceral fat area in non-obese diabetics compared to non-obese control group. However, no significant difference was observed between groups and the rest of the studied parameters.

Table 2: Comparison between diabetics and controls according to the BMI

\begin{tabular}{|c|c|c|c|c|c|}
\hline Variables & $\begin{array}{l}\text { Obese } \\
\text { diabetics } \\
\text { Mean } \pm S D \\
N=20\end{array}$ & $\begin{array}{l}\text { Non-obese } \\
\text { diabetics } \\
\text { Mean } \pm S D \\
N=20\end{array}$ & $\begin{array}{l}\text { Obese } \\
\text { controls } \\
\text { Mean } \pm S D \\
N=20\end{array}$ & $\begin{array}{l}\text { Non-obese } \\
\text { controls } \\
\text { Mean } \pm S D \\
N=20\end{array}$ & p-value \\
\hline Age (yrs) & $49.8 \pm 3.8$ & $50.8 \pm 3.8$ & $50.2 \pm 3.8$ & $50.2 \pm 3.5$ & $>0.8$ \\
\hline$B M I\left(\mathrm{~kg} / \mathrm{m}^{2}\right)$ & $33.7 \pm 2.7^{a}$ & $22.4 \pm 1.6^{b}$ & $33.2 \pm 2.1^{a}$ & $22.3 \pm 1.6^{b}$ & $<0.001 *$ \\
\hline WHR & $1.1 \pm 0.1^{a}$ & $0.7 \pm 0.06^{b}$ & $1.1 \pm 0.1^{a}$ & $0.7 \pm 0.06^{b}$ & $<0.001 *$ \\
\hline Duration of diabetes (yrs) & $6.0 \pm 2.6$ & $6.1 \pm 3.8$ & - & - & $>0.9$ \\
\hline$S B P(\mathrm{mmHg})$ & $129.8 \pm 8.5^{a}$ & $131.0 \pm 7.8^{a}$ & $123.0 \pm 8.0^{b}$ & $119.8 \pm 6.6^{c}$ & $<0.001 *$ \\
\hline$D B P(m m H g)$ & $79.0 \pm 8.5$ & $80.0 \pm 8.1$ & $78.0 \pm 6.8$ & $75.5 \pm 4.3$ & $>0.2$ \\
\hline$F P G(\mathrm{mg} / \mathrm{dl})$ & $210.3 \pm 38.4^{a}$ & $175.9 \pm 32.3^{b}$ & $97.8 \pm 5.1^{c}$ & $89.3 \pm 5.3^{c}$ & $<0.001 *$ \\
\hline Insulin $(\mu I U / m I)$ & $26.5 \pm 5.2^{a}$ & $23.0 \pm 2.9^{b}$ & $13.1 \pm 1.7^{c}$ & $7.0 \pm 1.1^{d}$ & $<0.001 *$ \\
\hline$H O M A_{I R}$ & $13.5 \pm 3.2^{a}$ & $10.0 \pm 1.6^{b}$ & $3.1 \pm 0.4^{c}$ & $1.5 \pm 0.2^{d}$ & $<0.001 *$ \\
\hline Total Cholesterol (mg/dl) & $214.4 \pm 26.1^{a}$ & $209.5 \pm 22.6^{a}$ & $199.6 \pm 17.9^{b}$ & $188.3 \pm 12.8^{c}$ & $<0.001 *$ \\
\hline Triacylglycerol (mg/dl) & $129.4 \pm 35.8^{a}$ & $126.5 \pm 29.1^{a}$ & $121.4 \pm 25.3^{a b}$ & $106.5 \pm 17.6^{b}$ & $<0.05^{*}$ \\
\hline$H D L-c(m g / d l)$ & $40.9 \pm 7.9^{a}$ & $41.1 \pm 8.1^{a}$ & $50.6 \pm 6.5^{b}$ & $49.4 \pm 3.4^{b}$ & $<0.001 *$ \\
\hline$L D L-c \quad(m g / d l)$ & $145.3 \pm 25.2^{a}$ & $143.0 \pm 24.3^{a}$ & $121.6 \pm 19.4^{b}$ & $117.8 \pm 11.5^{b}$ & $<0.001 *$ \\
\hline$H b A_{1 c}(\%)$ & $7.8 \pm 1.4^{a}$ & $7.9 \pm 1.5^{a}$ & $5.7 \pm 0.3^{b}$ & $5.7 \pm 0.3^{b}$ & $<0.001 *$ \\
\hline Visfatin (ng/ml) & $53.9 \pm 10.4^{a}$ & $34.3 \pm 7.8^{b}$ & $45.2 \pm 9.4^{c}$ & $20.3 \pm 5.2^{d}$ & $<0.001 *$ \\
\hline$R B P-4(\mu \mathrm{g} / \mathrm{ml})$ & $52.3 \pm 7.2^{a}$ & $40.3 \pm 9.4^{b}$ & $32.4 \pm 6.1^{c}$ & $21.2 \pm 3.5^{d}$ & $<0.001 *$ \\
\hline Visceral fat area $\left(\mathrm{cm}^{2}\right)$ & $105.7 \pm 13.8^{a}$ & $84.7 \pm 9.0^{b}$ & $102.0 \pm 11.6^{a}$ & $64.8 \pm 8.8^{c}$ & $<0.001 *$ \\
\hline SF thickness (mm) & $14.4 \pm 3.9^{a}$ & $11.0 \pm 4.2^{b}$ & $14.5 \pm 3.6^{a}$ & $9.2 \pm 3.8^{\boldsymbol{b}}$ & $<0.001 *$ \\
\hline
\end{tabular}

* Different symbols indicate significance 


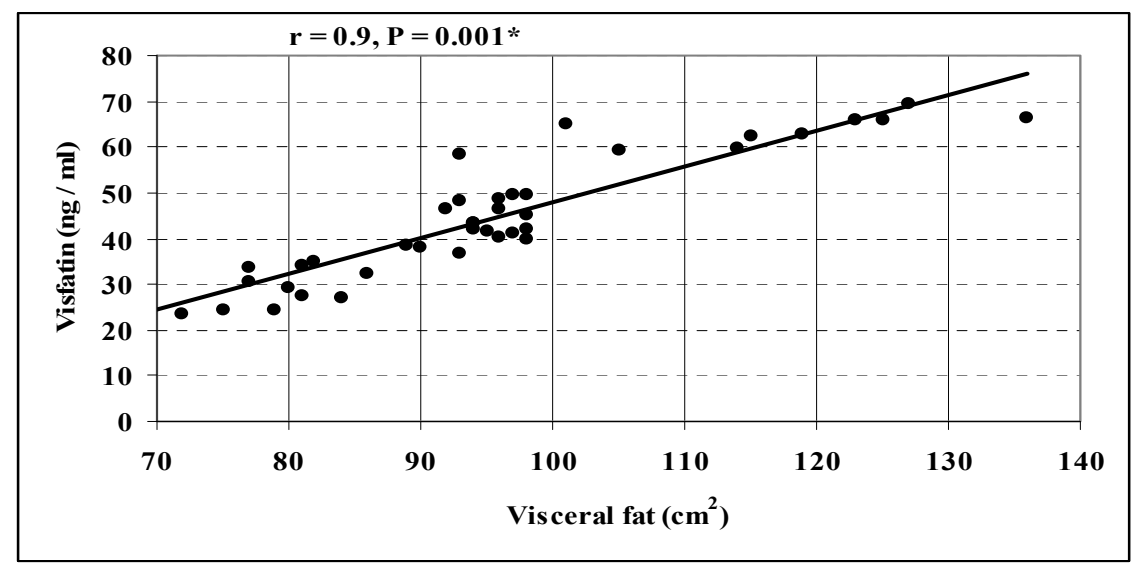

Figure 4: Correlation between plasma visfatin and visceral fat area in diabetic patients.

Pearson correlation analysis was used to identify the factors that most closely related to visfatin and RBP-4 in diabetic patients as shown in table 3. Plasma visfatin levels were correlated positively with RBP-4, BMI, WHR, insulin, and HOMA $\mathrm{HR}_{\mathrm{I}}$ (respectively, $\mathrm{r}=0.4, \mathrm{p}<0.02 ; \mathrm{r}=0.8$, $\mathrm{p}<0.001 ; \mathrm{r}=0.9, \mathrm{p}<0.001 ; \mathrm{r}=0.5$, $\mathrm{p}<0.003 ; \mathrm{r}=0.5, \mathrm{p}<0.002)$ and visceral fat area $(\mathrm{r}=0.9, \mathrm{p}<0.001)$ Figure 4; whereas it was negatively correlated with SBP $(\mathrm{r}=-0.3, \mathrm{p}<$ 0.04). There was no significant correlation between plasma visfatin and the rest of the studied parameters. Plasma RBP-4 levels were correlated positively with visfatin $(\mathrm{r}=0.4, \mathrm{p}<$ $0.02)$, BMI ( $\mathrm{r}=0.5, \mathrm{p}<0.002)$, WHR $(\mathrm{r}=0.4, \mathrm{p}<0.006)$, FPG $(\mathrm{r}=0.4, \mathrm{p}<$ $0.01)$, insulin $(\mathrm{r}=0.4, \mathrm{p}<0.004)$, $\mathrm{HOMA}_{\mathrm{IR}} \quad(\mathrm{r}=0.6, \mathrm{p}<0.001)$ and fatty liver $(r=-0.7, p<0.001)$. There was no significant correlation between plasma RBP-4 and age, sex, duration of diabetes, blood pressure, lipid profile, $\mathrm{HbA}_{1 \mathrm{c}}$, visceral fat area, and subcutaneous fat. 
correlated positively with visfatin $(\mathrm{r}$ $=0.6, \mathrm{p}<0.001)$, BMI $(\mathrm{r}=0.6, \mathrm{p}<$ $0.001)$, WHR $(r=0.6, p<0.001)$, FPG $(\mathrm{r}=0.5, \mathrm{p}<0.01)$, insulin $(\mathrm{r}=0.7, \mathrm{p}<$ $0.001)$ (Figure 5), $\operatorname{HOMA}_{\mathrm{IR}}(\mathrm{r}=0.7$, $\mathrm{p}<0.001)$ and fatty liver $(\mathrm{r}=0.7, \mathrm{p}<$ 0.001 ). In obese control group, plasma visfatin levels showed significant positive correlation with BMI $(\mathrm{r}=0.6$, $\mathrm{p}<0.006)$, WHR $(\mathrm{r}=0.7, \mathrm{p}<0.001)$ and visceral fat $(\mathrm{r}=0.8$, $\mathrm{p}<0.001)$. While, plasma RBP-4 levels were positively correlated with fatty liver only $(r=0.7, p<0.001)$. However, in non-obese control group, plasma visfatin levels were correlated positively with visceral fat only $(r=$ $0.7, \mathrm{p}<0.001)$. Plasma RBP-4 levels were correlated positively with fasting insulin levels $(\mathrm{r}=0.6, \mathrm{p}<0.001)$ and HOMA $_{I R}(r=0.6, p<0.001)$ in nonobese control subjects.

Table 4 shows stepwise multiple regression analysis using plasma visfatin as independent variable and various clinical and biochemical parameters as dependent variables in diabetic patients, only plasma visfatin level remained positively correlated with visceral fat area (VFA) and
WHR. When each group was analyzed separately, plasma visfatin level remained, also, positively correlated with visceral fat and WHR in obese diabetic group $(\mathrm{p}=0.001$, in both) and only with visceral fat in non-obese diabetic group ( $\mathrm{p}<0.001)$. In control group, plasma visfatin was positively correlated with visceral fat $(p<0.001)$, even after separation into obese and non-obese groups.

Stepwise multiple regression analysis using plasma RBP-4 as an independent variable and various clinical and biochemical parameters as dependent variables in diabetic patients, showed that fatty liver $(\mathrm{p}<$ $0.001)$, BMI $(\mathrm{p}<0.001)$ and insulin resistance $(\mathrm{p}<0.05)$ were positively associated with plasma RBP-4, and only fatty liver was positively correlated with RBP-4 in both obese and non-obese diabetic groups, separately. However, in control group, plasma RBP-4 was positively correlated with fatty liver $(\mathrm{p}<0.001)$ and $\mathrm{HOMA}_{\mathrm{IR}}(\mathrm{p}<0.04)$, and with fatty liver only $(p<0.001)$ in obese control group and with insulin only $(\mathrm{p}<$ 0.009 ) in non-obese control group. 
Table 4: Stepwise multiple regression analysis of Visfatin and clinical and biochemical parameters in diabetics patients

\begin{tabular}{|l|l|l|l|l|}
\hline Variables & B & $\begin{array}{l}\text { 95\% Confidence } \\
\text { intervals }\end{array}$ & $\boldsymbol{P}$ & P-value \\
\hline $\begin{array}{l}\text { Visceral fat area } \\
\text { Waist hip ratio }\end{array}$ & 0.5 & $0.4-0.7$ & 0.6 & $<0.001^{*}$ \\
\hline
\end{tabular}

$$
\mathrm{R}^{2}=0.88 \quad \mathrm{SE}=4.8 \quad \mathrm{P}=0.0001^{*}
$$

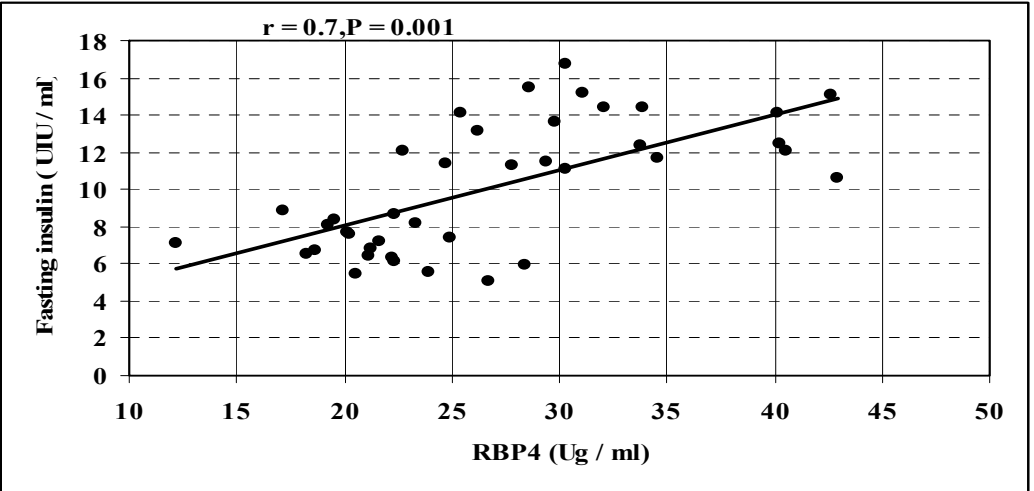

Figure 5: Correlation between RBP-4 and fasting insulin in control subjects (obese and non-obese)

\section{DISCUSSION}

Type 2 diabetes mellitus is characterized by target-tissue resistance to insulin. It is strongly linked to obesity as over $80 \%$ of diabetics are obese (30). Insulin resistance is the core pathogenic factor for diabetes. In addition, it is, also, strongly associated with obesity, hypertension and cardiovascular disease $^{(\mathbf{3 0})}$. The new adipocytes derived hormones visfatin and retinol binding protein-4 (RBP-4) may be an important link between increased fat mass and insulin resistance and disorder of glucose metabolism in diabetes. To investigate whether the levels of visfatin, a recently characterized peptide, and the fat derived factor RBP-4 are related to adiposity and serve as determinants of insulin sensitivity in diabetic and obese subjects, the present study was conducted to examine the relationship between plasma visfatin and RBP-4 and body composition, abdominal fat distribution, and insulin sensitivity in type 2 diabetes mellitus and obesity.

Visfatin corresponds to pre-B cell colony-enhancing factor, a $52-\mathrm{kDa}$ cytokine secreted by activated lymphocytes $^{(6)}$ and is up-regulated in neutrophils and monocytes after exposure to inflammatory stimuli ${ }^{(31-}$ 33). Previous reports have raised questions regarding the origin and clinical relevance of visfatin, as it is ubiquitously expressed in different

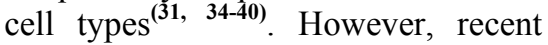
studies support the view that visfatin is a true adipokine that is clearly 
expressed in human adipocytes ${ }^{(33,41,42)}$. It was, also, shown that hyperglycemia induced visfatin overexpression in cultured human adipocytes $^{(\mathbf{4 1})}$. There have been contradictory findings on the association between visfatin and obesity. Haider et al. ${ }^{(\mathbf{4 3})}$ showed that visfatin levels were substantially increased in morbidly obese individuals and gastric banding surgery lowered the circulating visfatin levels in them. However, a recent study showed that the plasma levels of visfatin were significantly lower in obese subjects ${ }^{(\mathbf{4 2})}$

In the current study, it was found that plasma visfatin levels were significantly higher in the diabetics compared with obese and non-obese control subjects. Furthermore, visfatin levels in obese diabetics were significantly higher compared to nonobese diabetics. Similar findings were reported in a previous study ${ }^{(39)}$, which had suggested that the increased circulating levels and messenger RNA expression of visfatin in the diabetic subjects may be related to their increased adipose tissue mass. Also, the present study demonstrated that plasma visfatin levels showed a significant positive correlation with BMI and waist / hip ratio. This finding supports the studies of Berndt et $\mathrm{al}^{(\mathbf{9 )}}$ and Haider et al. ${ }^{(\mathbf{4 3})}$ who reported that visfatin is associated with obesity.

Visfatin is preferentially secreted by visceral fat cells and increased in obesity and type 2 diabetes mellitus ${ }^{(5)}$. This is considered to reflect an impairment of visfatin signaling or a dysregulation in its biosynthesis ${ }^{(5,7)}$. Visfatin levels correlate with visceral adipose tissue $\mathrm{(5,9)}^{\mathbf{5}}$ and consequently any increase in visfatin could indicate an increased visceral fat mass, which is usually associated with insulin resistance. Thus, considering the insulin mimetic properties of visfatin, the increase in visfatin might be regarded as compensation for decreased insulin mediated glucose uptake, eventually by increased GLUT-4 transcription. Along this line, the present study showed a significant positive correlation between visfatin and $\mathrm{HOMA}_{\mathrm{IR}}$, as well as insulin levels in the diabetic group in simple regression analysis but not in multiple regression analysis. This finding is in accordance with the study of Chen et al. ${ }^{(\mathbf{1 0})}$ who showed a significant association between visfatin and $\mathrm{HOMA}_{\mathrm{IR}}$, and in contrast to other studies that showed a lack of association between visfatin and insulin resistance ${ }^{(\mathbf{9 , 4 4})}$. Only visceral fat area remained significantly associated with plasma visfatin level in multiple regression analysis in all the studied groups. On the other hand, plasma visfatin did not correlate with BMI or other biomarkers such as, blood pressure and lipid profiles parameters in a multiple regression analysis. These facts are consistent with findings ${ }^{(10)}$ that visfatin is mainly secreted in the visceral fat and not subcutaneous fat, and may suggest that the pathogenetic mechanism of visfatin in type 2 diabetes mellitus is different from that of insulin resistance.

RBP-4 is another factor derived from fat cells, has recently been reported to provide a link between obesity and insulin resistance modulating glucose homeostasis and 
therefore possibly involved in the development of insulin resistance ${ }^{(\mathbf{1 2})}$. RBP-4 expression is increased in the adipose tissue of adipose-glucose transporter 4 (GLUT4) knockout mice and the serum levels of RBP-4 are elevated in insulin-resistant mice ${ }^{(\mathbf{1 2})}$.

The current study extends the research on RBP-4 to humans and showed a correlation between RBP-4 levels and the magnitude of insulin resistance in subjects with obesity, and type 2 diabetes mellitus. In the present study, plasma RBP-4 levels were significantly higher in diabetic group when compared to control subjects. Moreover, RBP-4 levels were positively correlated with bodymass index, and waist-to-hip ratio. This is in agreement with the recent study of Graham et al. ${ }^{(11)}$ who found a significant increase in RBP-4 in type 2 diabetics and obese subjects, and, also, found that the elevated RBP-4 levels correlate positively with components of the metabolic syndrome such as body mass index, waist circumference, triacylglycerol, and systolic blood pressure. Also, this is in accordance with the previous study of Yang et al. ${ }^{(\mathbf{1 2})}$ who showed an unequivocal difference between normal and obese subjects, with or without diabetes, in terms of circulating RBP-4 concentrations. They found that it was significantly higher in obese diabetics compared to lean diabetics and non-diabetic. On the contrary to these findings, Cho et al. ${ }^{(45)}$ found that glucose tolerance status had only a slight effect on plasma RBP-4 concentrations. This is probably attributable to the narrow BMI range shown by their study subjects. This was, also, in disagreement with Janke et al., (46), who found that RBP-4 gene expression in adipose tissue was significantly reduced in obese subjects. They, also, detected no difference in RBP-4 serum levels between lean, overweight, and obese subjects $^{(\mathbf{4 6})}$. The present study, also, showed that RBP-4 was correlated with insulin resistance even in nondiabetic subjects. These results indicate that RBP-4 could be used as an index of insulin sensitivity. The present findings regarding the relationships of circulating RBP4 with insulin resistance are consistent with previous reports ${ }^{(11,14)}$. However, other studies did not find significant relationship between them ${ }^{(\mathbf{4 6})}$.

The RBP-4 gene is located on chromosome 10q24 in humans in a region contains at least one interesting candidate gene, hexokinase 1 , the gene encoding a key enzyme in the initial step of glucose metabolism ${ }^{(47)}$. Furthermore, increased serum RBP-4 levels are known to stimulate hepatic gluconeogenesis through stimulation of phosphoenolpyruvate carboxyinase $^{(12)}$. Study data from Cho and colleagues $^{(\mathbf{4 5})}$ demonstrated elevated RBP-4 levels in patients with impaired glucose tolerance and type 2 diabetes mellitus. In addition, plasma glucose levels increased with plasma RBP-4 quartiles. Similar results were found in the present study.

In the present study, there was consistent increase of visfatin and retinol binding protein- 4 in diabetic and control subjects. The good correlation between the increase of visfatin and RBP-4 could indicate a common cause for the increased levels of both parameters, such as increased 
visceral obesity. Another explanation is that RBP-4 impairs insulin signaling in skeletal muscle through reduction in insulin-stimulated tyrosine phosphorylation of insulin receptor substrate-1 (IRS-1) at tyrosine residue 612 , an important site for the p85 subunit of phosphoinositide3-kinase ${ }^{(\mathbf{1 2})}$. Thus increased RBP-4 could lead to insulin resistance, which is followed by a compensatory hypersecretion of visfatin which is known to exert insulin mimetic properties ${ }^{(48)}$.

Visceral and subcutaneous adipose tissue display important metabolic differences. Thus, visceral obesity is mainly associated with obesity-related cardiovascular and metabolic alterations ${ }^{(49)}$. Indeed, adipocytokines, such as visfatin, are mainly expressed in visceral fat ${ }^{(5)}$. Therefore, the present study looked at the association of visceral, and subcutaneous, as well as fat deposition in the liver with plasma visfatin and RBP-4 in the studied groups. Visceral fat showed a significant correlation with plasma visfatin levels, whereas, subcutaneous fat, and fatty liver did not show such an association with plasma visfatin levels. Furthermore, according to the results of stepwise multiple regression analysis, plasma visfatin concentrations were correlated with visceral adipose tissue in all the studied groups. This study thus supports the report by Fukuhara et al. ${ }^{(5)}$ that visfatin is associated with visceral fat but not subcutaneous fat, but Berndt et al. ${ }^{(9)}$ did not find an association between plasma visfatin and visceral fat area. A recent study demonstrated that visfatin messenger
RNA may be differentially regulated in subcutaneous abdominal and visceral fat ${ }^{(\mathbf{4 1})}$. The presence of strong correlation between visfatin and visceral fat confirmed the accuracy of measuring visceral fat by ultrasound rather than by other modalities. Being simple and non invasive, other studies looked for using ultrasound in assessment of visceral fat. This is in agreement with Hirooka et al., (20), who concluded that measurement of visceral fat by ultrasound is as effective as computerized tomography.

Since the liver is the major source of RBP-4 production in rodents and probably also, in humans ${ }^{\mathbf{( 5 0 )}}$ and because ectopic fat deposition in the liver represents an insulin resistant state ${ }^{(51-53)}$, the present study tested whether circulating RBP-4 is elevated under increased fat accumulation in the liver. Particularly hepatic fat accumulation was found to decrease insulin activation of glycogen synthase and increased gluconeoenesis, thus, contributing to wholebody insulin resistance ${ }^{(\mathbf{5 4 )}}$. Moreover, prevention of fatty liver ${ }^{(\mathbf{5 2})}$ and decrease in hepatic fat accumulation were found to decrease insulin resistance ${ }^{(53)}$. On the other hand, a prior study, revealed a correlation of RBP-4 to waist/hip ratio, suggesting an association between RBP-4 levels and abdominal obesity, however no correlation between RBP-4 levels and percent body fat was found ${ }^{(11,44)}$. The current study showed that plasma RBP-4 levels did not correlate with visceral or subcutaneous fat but positively correlated with fat deposition in the liver. This is in accordance with the recent study of 
Stefan et al. ${ }^{(14)}$ who found that RBP-4 correlated positively with fatty liver but not with visceral or subcutaneous fat. Also, a recent study of Gavi et al. ${ }^{(13)}$ found that serum RBP-4 levels were strongly correlated with the trunk fat and not with peripheral fat ${ }^{(\mathbf{1 3})}$. However, in disagreement with the current study, a recent study of Jia et al. ${ }^{(55)}$ showed that serum RBP-4 level was positively correlated with visceral adiposity in Chinese subjects with and without type 2 diabetes mellitus, and subjects treated with rosiglitazone showed reduced visceral fat mass, decreased serum RBP-4 levels and improved insulin sensitivity.

Thus, the close correlations of circulating RBP-4 with fatty liver and insulin resistance may imply that fatty liver is a source of increased RBP-4 production in humans possibly due to the relationship with liver fat and /or due to the stimulatory effects of RBP4 on gluconeogenesis ${ }^{(\mathbf{1 2})}$. In this aspect, circulating RBP-4 might serve as a biomarker of fatty liver.

In conclusion, the present study reported that both plasma visfatin and RBP-4 levels were significantly higher in type 2 diabetics and obese individuals. Regarding body fat distribution, plasma visfatin was found to be strongly correlated with visceral fat only but not with subcutaneous fat, thus suggesting a divergent regulation of this adipokine in different fat depots. These data support that increased visfatin may be a feedback mechanism preventing the deleterious effects of the expansion of the intra-abdominal depots on insulin sensitivity, or simply an epiphenomenon that might be useful as a surrogate marker of increased visceral fat mass and cardiovascular risk. On the other hand, plasma RBP4 level correlated with insulin resistance and fat deposition in the liver, so, measurement of plasma RBP-4 could become a non-invasive and accessible method for assessing the risks of impaired glucose tolerance, type 2 diabetes mellitus, and cardiovascular disease. Studies of the roles of visfatin and RBP-4 and the amount of visceral fat will shed new light on prevention and treatment of type 2 diabetes, and open a new field for the development of new drugs to improve insulin resistance.

\section{REFERENCE}

1. Kahn BB, Flier JS (2000): Obesity and insulin resistance. J. Clin. nvest., 106: 473-481.

2. Kershaw EE, Flier JS (2004): Adipose tissue as an endocrine organ. J. Clin. Endocrinol.Metab., 89: 2548-56.

3. Wajchenberg BL (2000): Subcutaneous and visceral adipose tissue: their relation to the metabolic syndrome. Endocr. ev., 21: 697-738.

4. Thorne A, Lonnqvist F, Apelman J, Hellers G, Arner P (2002): A pilot study of long term effects of a novel obesity treatment: omentectomy in connection with adjustable gastric banding. Int.J.Obes.Relat.Metab.Disord., 26: 193-9.

5. Fukuhara A, Matsuda M, Nishizawa $M$, Segawa $K$, Tanaka M, Kishimoto K, Matsuki Y, Murakami M, 
Ichisaka T, Murakami H, Watanabe E, Takagi T, Akiyoshi M, Ohtsubo T, Kihara S, Yamashita S, Makishima M, Funahashi T, Yamanaka S, Hiramatsu R, Matsuzawa Y, Shimomura I (2005): Visfatin: a protein secreted by visceral fat that mimics the effects of insulin. Science 307: 426-430.

6. Samal B, Sun Y, Stearns G, Xie C, Suggs S, McNiece I (1994): Cloning and characterization of the cDNA encoding a novel human pre-B-cell colonyenhancing factor. Mol. Cell Biol.,14: 1431-1437.

7. Kralisch S, Klein J, Lossner U, Bluher M, Paschke R, Stumvoll M, Fasshauer M (2005): Hormonal regulation of the novel adipocytokine visfatin in 3T3-L1 adipocytes. J.Endocrinol., 185: 18.

8. Choi KC, Ryu OH, Lee KW, Kim HY, Seo JA, Kim SG, Kim NH, Choi DS, Baik SH, Choi KM (2005): Effect of PPAR-alpha and -gamma agonist on the expression of visfatin, adiponectin, and TNFalpha in visceral fat of OLETF rats. Biochem. Biophys. Res.Commun., 336: 747-753.

9. Berndt J, Klting N, Kralisch S, Kovacs P, Fasshauer M, Schn MR, Stumvoll M, Blüher M (2005): Plasma visfatin concentrations and fat depot-specific mRNA expression in humans. Diabetes 54: 2911-2916.

10. Chen MP, Chung FM, Chang DM, Tsai JC, Huang HF, Shin SJ, Lee YJ (2006): Elevated plasma level of visfatin/pre-B cell colonyenhancing factor in patients with type 2 diabetes mellitus. J. Clin. Endocrinol. Metab., 91: 295-299.

11. Graham TE, Yang $Q$, Bluher $M$, Hammarstedt A, Ciaraldi TP, Henry RR (2006): Retinol-binding protein 4 and insulin resistance in lean, obese, and diabetic subjects. N.Engl.J.Med., 354: 2552-63.

12. Yang $Q$, Graham TE, Mody N, Preitner F, Peroni OD, Zabolotny JM (2005): Serum retinol binding protein 4 contributes to insulin resistance in obesity and type 2 diabetes. Nature 436: 356-62.

13. Gavi S, Stuart LM, Kelly P, Melendez MM, Mynarick DC, Gelato MC, McNurlan MA (2007): Retinol-binding protein 4 is associated with insulin resistance and body fat distribution in nonobese subjects without type 2 diabetes. J. Clin. Endorinol. Metab., 92(5): 1886-1890.

14. Stefan N, Hennige AM, Staiger $H$, Machann J, Schick F, Scleicher E, Fritsche A, Harig HU (2007): High circulating retinol binding protein 4 is associated with elevated liver fat, but not with total, subcutaneous, visceral, or intramyocellular fat in humans. Diabetes Care 30(5): 1173-1178.

15. Snijder MB, Visser M, Dekker JM, Seidell JC, Fuerst T, Tylavsky F, Cauley J, Lang T, Nevitt M, Harris TB (2002): The prediction of visceral fat by dual- energy X-ray absorptiometry in the elderly: a comparison with computed tomography and anthropometry. Int. Relat. Metab. Disord., 26: 984-93.

16. Cnop M, Landchild MJ, Vidal J (2002): The concurrent 
accumulation of intra-abdominal and subcutaneous fat explains the association between insulin resistance and plasma leptin concentration: Distinct metabolic effects of 2 fat compartments. Diabetes 51: 1005-1015.

17. Dixon AK (1983): Abdominal fat assessed by computed tomography: sex difference in distribution. Clin. Radiol., 34: 189-191.

18. Owens S, Gutin B, Ferguson $M$, Allison J, Karp W, Le NA (1998): Visceral adipose tissue and cardiovascular risk factors in obese children. J.Pediatr., 133:4145.

19. Leite $\mathrm{CC}$, Wajchenberg BL, Radominski R, Matsuda D, Cerri GG, Halpern A (1992): Intra-abdominal thickness by ultrasonography to predict risk factors for cardiovascular disease and its correlation with anthropometric measurements. Metabolism 51: 1034-1040.

20. Hirooka M, Kumagi T, Kurose K (2005): A technique for the measurement of visceral fat by ultrasonography: Comparison of measurements by ultrasonography and computed tomography. Internal Medicine 44: 794-799.

21. World health organization (1998): Obesity: preventing and managing the global epidemic. Geneva.

22. American Diabetes Association (2005): Diagnosis and classification of diabetes mellitus. Diabetes Care 28: S37- S42.

23. Danilova LA and Lopatina NI (1986): Colorimetric method of determining glycosylated haemoglobin. Lab. Delo., 5:282-3.

24. Wahlefeld AW (1974): Triglyceride determination after enzymatic hydrolysis. In: Methods of enzymatic analysis; HU Berger ed., 2 ${ }^{\text {nd }}$ English ed. (translated from third German ed.), Verlag Chemie Weinheim and academic press, Inc. NY and London Vol. 4, pp 1813-1835.

25. Flegg HM (1973): An investigation for the determination of serum cholesterol by an enzymatic method. Ann.Clin.Biochem., 10: 79-84.

26. Friedwald WT; Levy RI, Fredrickson DS (1972): Estimation of low density cholesterol in plasma without use of the preparative ultracentrifugation. Clin.Chem., 18: 499.

27. Trinder L (1969): Determination of blood glucose using an oxidase-peroxidase system with a non- carcinogenic chromagen. Ann.Clin.Biochem., 6: 24-29.

28. Matthews DR, Hosker JP, Rudenski AS, Naylor BA, Treacher DF, Turner RC (1985): Homeostasis model assessment: insulin resistance and beta-cell function from fasting plasma glucose and insulin concentrations in man. Diabetologia 28: 412-419.

29. Altman GA (1991): In Altman GA (ed.): Practical statistics for Medical Research, Chapman and Hall, London, p.92.

30. McTernan CL, McTernan PG, Harte AL, Levick PL, Barnett AH, Kumar S (2002): Resistin, central obesity, and type 2 diabetes. Lancet 359: 46-47 
31. Jia SH, Li Y, Parodo J, Kapus A, Fan L, Rotstein O (2004): Pre-B cell colony-enhancing factor inhibits neutrophil apoptosis in experimental inflammation and clinical sepsis. J. Clin. Invest., 113: 1318-27.

32. Subrahmanyam YV, Yamaga S, Prashar Y, Lee HH, Hoe NP, Kluger Y (2001): RNA expression patterns change dramatically in human neutrophils exposed to bacteria. Blood 97: 2457-68.

33. Nau GH, Richmond JF, Schlesinger A, Jennings EG, Lander ES, Young RA (2002): Human macrophage activation programs induced by bacterial pathogens. Proc. Natl. Acad. Sci., 99: 1503-8.

34. Ognjanovic S, BryantGreenwood GD (2002): Pre-Bcell colony-enhancing factor, a novel cytokine of human fetal membranes. Am. J. Obstet. Gynecol., 187: 1051-8.

35. Curat CA, Wegner V, Sengenes C, Miranville A, Tonus C, Busse R, Bouloumie A (2006): Macrophages in human visceral adipose tissue: increased accumulation in obesity and a source of resistin and visfatin. Diabetologia 49: 744-7.

36. Arner P (2006): Visfatin: A true or false trail to type 2 diabetes mellitus. J. Clin. Endocrinol. Metab., 91: 28-30.

37. Hug C, Lodish HF (2005): Visfatin: a new adipokine. Science 307: 366-7.

38. Rongvaux A, Shea RJ, Mulks MH, Gigot D, Urbain J, Leo O (2002): Pre-B-cell colony- enhancing factor, whose expression is up-regulated in activated lymphocytes, is a nicotinamide phosphoribosyltransferase, a cytosolic enzyme involved in NAD biosynthesis. Eur. J. Immunol., 32: 3225-34.

39. Van der Veer E, Nong $Z$, O'Neil C, Urquhart B, Freeman D, Pickering JG (2005): Pre-Bcell colony-enhancing factor regulates $\mathrm{NAD}+$-dependent protein deacetylase activity and promotes vascular smooth muscle cell maturation. Circ.Res., 97: 2534.

40. Kitani T, Okuno S, Fujisawa $H$ (2003): Growth phase-dependent changes in the subcellular localization of pre-B-cell colonyenhancing factor. FEBS (Lett.), 544: 74-78.

41. Haider DG, Schaller G, Kapiotis S, Maier C, Luger A, Woltz M (2006): The release of the adipokine visfatin is regulated by glucose and insulin. Diabetologia 49: 1909-1914.

42. Pagano C, Pilon C, Oliveri M, Mason P, Fabris R, Serra R (2006): Reduced plasma visfatin/pre-B cell colony enhancing factor in obesity is not related to insulin resistance in humans. J. Clin. Endocrinol. Metab., 91: 3165-3170.

43. Haider DG, Schindler $K$, Schaller G, Prager G, Wolzt M, Ludvik B (2006): Increased plasma visfatin concentrations in morbidly obese subjects are reduced after gastric banding. J. Clin. Endocrinol. Metab., 91: 1578-1581. 
44. Hammarstedt A, Pihlajamaki J, Sopasakis VR, Gogg S, Jansson PA, Laakso M (2006): Visfatin is an adipokine but it is not regulated by thiazolidinediones. J. Clin. Endocrinol. Metab., 91: 1181-4.

45. Cho YM, Youn BS, Lee H, Lee N, Min SS, Kwak SH, Lee HK, Park KS (2006): Plasma retinolbinding protein-4 concentrations are elevated in human subjects with impaired glucose tolerance and type 2 diabetes. Diabetes Care 29: 2457-2461.

46. Janke J, Engeli S, Boschmann M, Adams F, Bohnke J, Luft FC, Sharma AM, Jordan J (2006): Retinol-binding protein 4 in human obesity. Diabetes 55: 2805-2810.

47. Meigs JB, Panhuysen CI, Myers RH, Wilson PW, Cupples LA (2002): A genomewide scan for loci linked to plasma levels of glucose and $\mathrm{HbA}_{1 \mathrm{c}}$ in a community-based sample of Caucasian pedigrees: he Framingham Offspring Study. Diabetes 51: 833-40.

48. Schindler K, Haider D, Wolzt A, Rieger B, Gmeinhart A, Luger P, Nowotny P, Ludvik B (2006): Impact of antiretroviral therapy on visfatin and retinol binding protein 4 in HIV-infected subjects. Eur.J.Clin.Invest., 36: 640-646.

49. Matsuzawa Y (2006): The metabolic syndrome and adipokines. FEBS (Lett.), 580: 2917-21.

50. Blaner WS (1989): Retinolbinding protein: the serum transport protein for vitamin A. Endocr. Rev., 19:308-316.

51. Yki-Jarvinen H, Westerbacka J (2005): The fatty liver and insulin resistance. Curr. Mol. Med., 5: 287-295.

52. Roden M (2006): Mechanisms of Disease: hepatic steatosis in type 2 diabetes-pathogenesis and clinical relevance. Nat. Clin. Pract. Endocrinol. Metab., 2: 335348.

53. Petersen KF, Dufour S, Befroy D, Lehrke M, Hendler RE, Shulman GI (2005): Reversal of nonalcoholic hepatic steatosis, hepatic insulin resistance, and hyperglycemia by moderate weight reduction in patients with type 2 diabetes. Diabetes 54: 603608.

54. Samuel VT, Liu ZX, Qu X, Elder BD, Bilz S, Befroy D, Romanelli AJ, Shulman GI (2004): Mechanism of hepatic insulin resistance in nonalcoholic fatty liver disease. J.Biol.Chem., 279: 32345-32353.

55. Jia W, Wu H, Bao Y, Wang C, Lu J, Junxi L, Zhu J, Xiang K (2007): Association of serum retinol binding protein 4 and visceral adiposity in Chinese subjects with and without type 2 diabetes. J.Clin.Endocrin.Metab., 92(8): 3224-3229. 


\section{تأثير البدانة على الفيزفاتين والبروتين-ء الرابط للرتينول فى البلازما فى وجود و

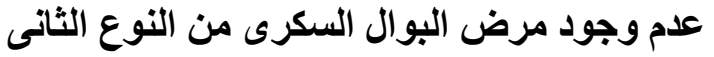

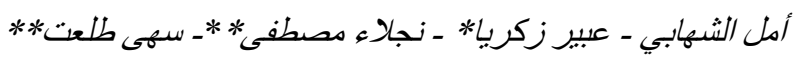

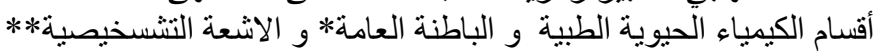 \\ كلية الطب - جامعة القاهرة}

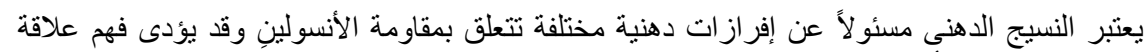

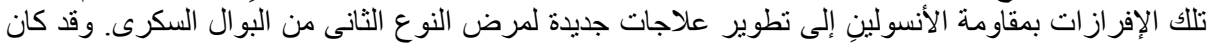

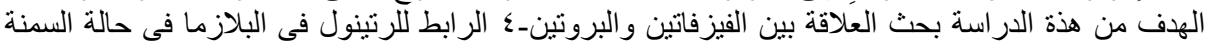

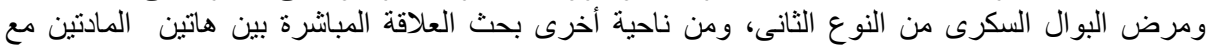

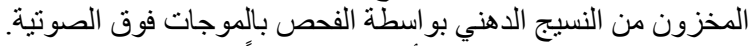

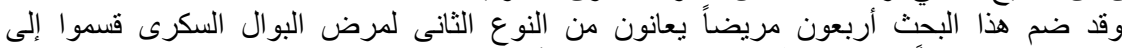

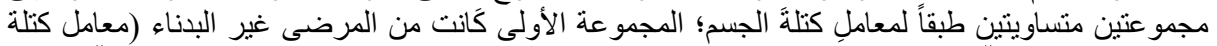

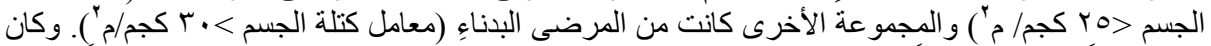

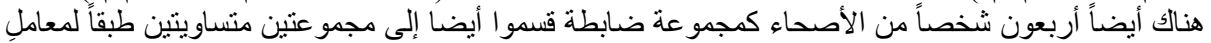
كتلة الجسم.

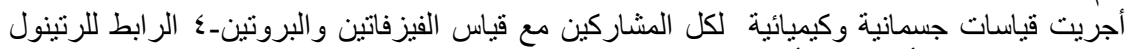

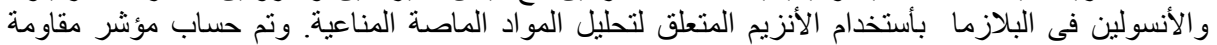

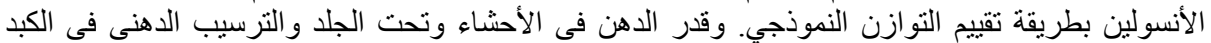

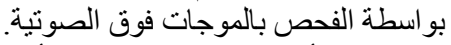

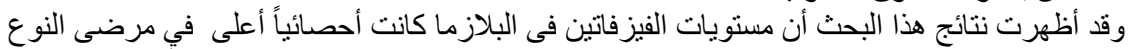

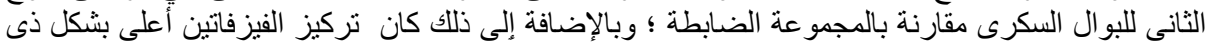

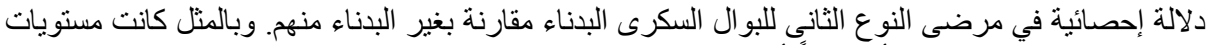

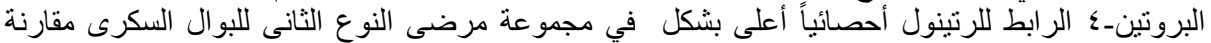

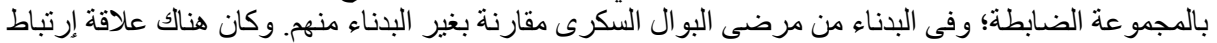

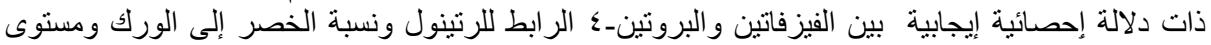

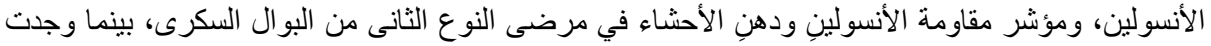

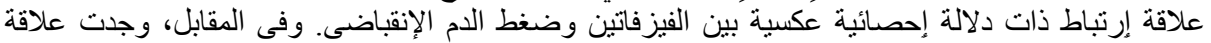

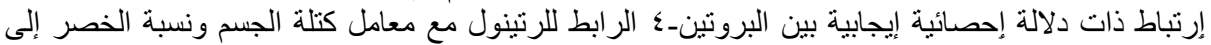

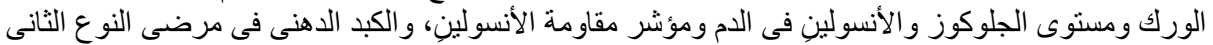

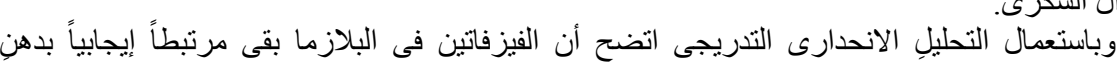
من البو ال السكرى.

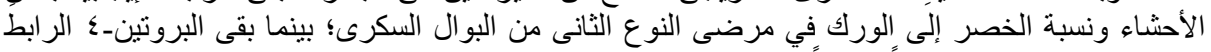

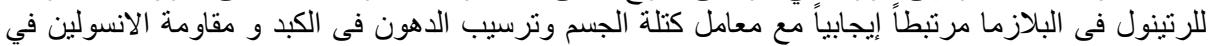

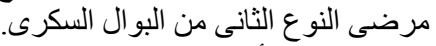

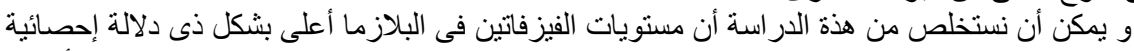

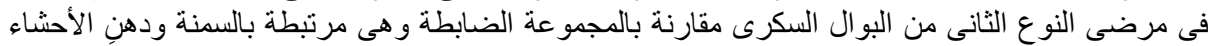

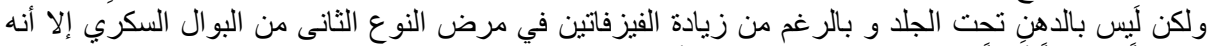

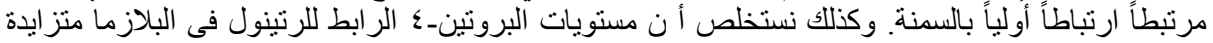

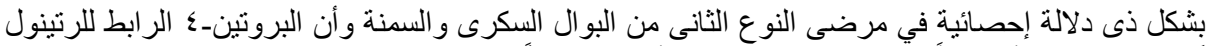

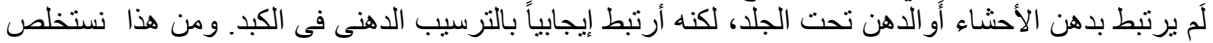

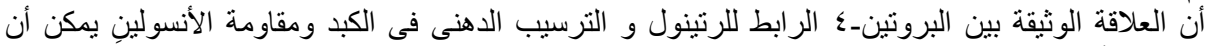

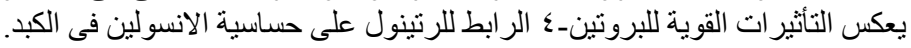

